\title{
How I see the Nutrition Challenges set by the ICN2 Framework for Action impinging on the UN Decade of Nutrition at mid-term
}

[The 2012 ICN2 Framework For Action is not dead. (https://search.yahoo.com/search?ei=utf8\&fr=tightropetb\& $p=I C N 2+$ Framework+of+action\&type $=Y 139$ F13 187601 090719) You may not even be aware of or remember it, but it is the very basis for the UN Decade of Action for Nutrition. (https://www.unscn.org/en/topics/un-decade-of-action-on-nutrition) Thus discussions about its key points are still relevant for the upcoming World Public Heath Nutrition Association Congress in Brisbane (https://wphna.org/). This World Nutrition commentary, in a way, attempts to go back to the Framework's weaknesses so that Congress attendees (and other WN readers) can think about the origins of why and what is 'not so good' in the Decade. There is a history behind the shortcomings of the Decade dating from 2012. The intention here is to prompt some corrective measures at the Decade's mid-term. Ideas for these could, hopefully, come up at the end of the Congress. (Maybe in its final declaration?) It is hoped that the critique here will help us, between now and the Congress, to reflect on important issues related to our responsibilities in public health nutrition. I invite counterpoints to my points. [NOTE: It is not the purpose of this article to specifically assess what has been done/not done at mid-term.]

\section{Points:}

1. ICN2's Framework for Action (FFA) never directly identified concrete points of action expected of Member States and of pertinent global agencies, especially UN agencies; nor was a clear role specified for public interest civil society organizations (PICSOs). It has been left to interpretation --and loopholes have been and are being used.

2. The food and nutrition situation in each country has yet to be assessed from a "right to nutrition" perspective as a prerequisite to set the appropriate priorities to formulate specific national plans of action. Clear commitments to claim-holder participation were simply lacking.

3. Actually, the opportunity was also missed by The Framework to consistently mention claim holders and duty bearers; instead, throughout, it used 'stakeholders' --a discredited term as bad as the term 'non-state actors' that does not discriminate between public and private sector actors. The suspicion must be that the drafters never took the right to nutrition seriously. (Note that the ICN2 Declaration, did not mention the right to nutrition at all!). (Vivero, J.L. Schuftan, C. "No right to food and nutrition in the SDGs: mistake or success?", BMJ Global Health, Vol.1, No.1, June 2016) 
4. Just speaking about the need for better food and nutrition governance, as the Framework does, has proven not to be enough. Wishfulness is not a strategy. We are talking here about the need to substantially reform the nutrition governance structure, particularly at global and national levels.

5. The Framework for Action called for a "cross-government, inter-sectoral governance mechanism”, including the engagement of local and intermediate level governments. We have done this before. Inter-sectoriality fizzles away and works poorly, especially when such mechanisms do not have the power to decide on budgets. On top of that, they are awfully top-down. Needed is an alternative or at least a combined bottom-centered approach.

6. Strategies proposed did not address people's day-to-day dietary choice options, particularly the contexts in which these choices are made, including the negative influence of heavy advertising of ultra-processed foods, especially to children. This leaves advocates of proposed public health nutrition strategies without a clear explicit focus regarding who of those in charge are to be targeted with the appropriate stern demands for change.

7. Only regular annual assessments of progress towards the progressive realization of the right to nutrition by national and local governments, as well as by public interest PICSO partners, will have a chance to enhance needed accountability. The agencies and organizations that would regularly assess progress or stagnation were never clearly identified.

8. Improving nutrition is not for economic gains; it is to improve every individual's well being and to maintain their dignity: Nutrition is a human right (HR)! That is the justification that should have been used --but was not. It is not about cost effectiveness, as claimed; it is about fulfilling and protecting a neglected HR!

9. The food systems approach used has too often left breastfeeding out! Also, some food systems experts focus heavily on agriculture and neglect the critical role of food and beverages manufacturers.

10. The Framework for Action says: "The private sector will facilitate more sustainable and nutritionally desirable diets only when it pays to do so". But the fact is that, if ever, public health rarely pays... so who are we kidding here? Hence, appropriate regulation, taxation, and incentives must be imposed on the private sector. Voluntary guidelines have not worked. Conflicts of interest and the use of loopholes are rife.

11. Improvements The Framework called for were importantly about nutrients. They ought to be about tackling the social determination of preventable malnutrition (that include nutrients). Moreover, no mention was made about sharing family meals; this is to be regretted and calls for reconsideration in what is left of the Decade to eventually pursue this alternative approach to the right to nutrition. 
12. It was never clear who was to take the priority actions that The Framework called for. Member States? Specific ministries? Others? Vagueness has bred vagueness. De-facto participation of relevant claim holders in monitoring priority actions was and is the way to go. Only this will help overcome the top-down character of The Framework.

13. The Framework further called for "Analyzing the causes, magnitude and dimensions of malnutrition, who is affected, as well as constraints to and opportunities for effective interventions at scale”. I ask: Only analyze? And then what? Participation of claim holders is a must here and was not mentioned. What is it that we do not yet understand about the causes that we need to reassess? Is not the real problem the lack of agreement on the causes behind the causes, because powerful actors making decisions have vested interests to protect?

14. We also read that bio-fortification has much potential for reducing micronutrients undernutrition. After many years of heavy investments, there is not much to show for this in the literature in terms of evidence of impact on a large scale, and it encourages technological fixes when what is needed is changes in diets as a whole --which are often primarily related to social and human rights conditions.

15. There is now ample evidence in the literature that reformulating ultra-processed foods is NOT a solution. We will only end up with junk food just a bit less junky, and industry will have whitewashed its conscience; it will improve its public image, and make further inroads into the needed consumption of fresh and unprocessed foods. The negative effects of ultra processed foods consumption need to be opposed with more direct measures.

16. The verbs used throughout The Framework are non-committal. How far will just encouragement go? What will 'promote', 'enable' and 'introduce measures' really do? None of these are binding and, therefore, are difficult to monitor in terms of accountability. Moreover, in several places, the Framework says there is a need to 'legislate', without adding 'and assure enforcement of'. These are good reasons for not taking the Framework for Action seriously --and, because of its influence on the Decade, it is worth criticizing it here, even these many years later.

17. Gender and socio-economic disaggregation of data sets was not sufficiently emphasized in the Framework. Quite significant reforms of health information systems will be needed to improve that situation: no mention of it can be found. Yet it was supposed to be an agenda for action!

18. Is 'nutrition sensitive' a new term used by the Framework? What was it supposed to replace? The social determinants of malnutrition? If so, why not use the latter as an already well-established concept? 
19. Calls for nutrition surveillance without commensurate community-based inputs is ultimately an exercise in chronicling malnutrition trends (for historians?) only. Yet this is what The Framework calls for. Also not mentioned is surveillance by whom, for what purpose, generating information to be used how? Needed are surveillance systems operated by claim holders in every community.

20. The social marketing called for in the Framework may teach people what to do/eat, but rarely helps them understand why. Too often it is simply used to manipulate people. Conversely, we should be including claim holders in active discussions and let them choose from a set of alternatives of what is to be done. This is the human rights way--that rarely needs expensive consultants.

21. We must make sure we do not imply, as the Framework does, that malnutrition (under and over) is primarily due to poor individual behavior. External factors importantly determine final behavior (including advertising). Therefore, nutrition education in isolation is not the answer. As carried out, nutrition education can and often does teach families to eat what they cannot afford.

22. "Dietary guidelines provide recommendations about the right amounts and combinations of foods in the form of simple dietary advice for the public and to assist in developing popular communication materials to ensure that the guidelines are used effectively". Let us be realistic. These 'recommendations' have been around for over 50 years. They focus on dietary behavior and on nutrients. How much have they helped? They will not achieve as much as needed unless guidelines zero-in on tackling the social determination of malnutrition (under and over).

23. The Framework's fixation on nutrients and micronutrients is a problem we inherited from the past. (C. Schuftan, V. Ramalingaswami, J. Levinson, "Micronutrient deficiencies and protein-energy malnutrition", The Lancet, Vol. 351 No. 9118 p 1812, June 13, 1998). The focus ought to be on local affordable diets. The nutritional (and family) value of these is what The Framework ought to have called for instead. [The recently developed NOVA classification of foods addresses this issue (https://www.cambridge.org/core/journals/public-healthnutrition/article/un-decade-of-nutrition-the-nova-food-classification-and-thetrouble-with-ultraprocessing/2A9776922A28F8F757BDA32C3266AC2A )].

24. "Nutrition education and promotion, face-to-face backed up by innovative communication approaches, including mass media, for adolescent girls and women, not only mothers, but also fathers and other caregivers, need to be improved, financed and scaled up to ensure greater outreach”. But if the content is wrong, the medium is irrelevant. Communication approaches need to counter all the misinformation being spread by the food and beverage industry and by selfappointed 'internet experts'. This must be coupled with human rights learning so as to empower claim holders to demand needed changes. Otherwise, nutrition education will become a bunch of letters to Santa Claus. 
25. To enforce accountability, both claim holders and duty bearers need to understand what accountability is in the context of the right to nutrition. Nothing on this is found in the Framework. Massive human rights learning will be needed for this. A task force must be set up in each Member State to prepare a well financed plan to be carried out on HR learning. Public interest CSOs will then act as empowered watchdogs to demand accountability.

26. The purpose of any monitoring and evaluation framework to be used on food and nutrition is to make sure that all actions are in accordance with and follow the progressive realization of the right to nutrition. Again, nothing on this in the Framework for Action document. Annual benchmarks in the long-term progressive realization of this right is what must be monitored, mostly monitoring processes-put-in-place rather than 'outcomes' which are all intermediate achievements only. Progress, stagnation or retrogression must be assessed annually if we want to achieve the SDG targets.

27. Finally, the Framework called for improved partnerships. I call your attention to the fact that partnerships are to be agreements between equals...you be the judge.

28. What have we learned from what was omitted or stated too vaguely in the ICN2 Framework for Action? This is the crucial point to address when we look at the Decade at mid-term.

\section{Given the above, here is how I see the challenges posed to the Decade of Nutrition at mid-term}

\section{Points for discussion in Brisbane:}

1. The experience from past UN-sponsored 'decades' has not been too good. We need to do better --this is the challenge. A significant difference will only be made by public interest CSOs and social movements pushing Member States to commit to funded action plans and then holding them accountable for these plans on a year-to-year basis. Therein lies the challenge, since needed changes will NOT come from the top... The topic to discuss is how realistic an outlook this is and what it will take in terms of new commitments. In other words, is this sort of accountability really feasible and what will it take?

2. Moreover, it is time we begin talking about food-and-nutrition-security and NOT food security and nutrition... Actually, better even, we need to get UN agencies to adopt the already widely accepted concept of food sovereignty. Consequent with the critique of the Framework for Action, UN agencies have to be lobbied to stop using the concept of nutrition-sensitive interventions that only is a biased substitute for tackling the social determination of nutrition. What contribution can our Congress make in this domain? 
3. Critical, and as soon as possible, is to refocus the Decade on the HR framework, clearly identifying claim holders and duty bearers and doing a capacity analysis of what the expected roles are that pertain to both groups followed by a gap analysis showing where these actors are not living up to what they ought to be doing. A massive HR learning process is the only thing that will lead to this. A process of empowerment of claim holders to organize, mobilize and demand needed changes is key. Without this, we can anticipate little happening or just token steps to be taken to tackle the real basic causes of malnutrition in all its forms. WHO and FAO do give lip service to this HR refocusing. Can our Brisbane Congress hold them more accountable on deeds in this direction? Is that sort of accountability really feasible and what will it take?

4. Most importantly, it is not for us to top-down decide priorities for what is left of the Decade! It is the claim holders suffering violations of their right to nutrition who must lead in deciding priority actions. We need to hold discussions on how much of this is being done, and if not much, why? Pointed demands on this issue could flow from our Congress given the fact that the core issue of the Decade is a push or a pull question. Only 'pulling' from claim holders below will move the Decade ahead. UN and other international agencies are currently doing little to push Member States to commit on this work with claim holders; evidence is clear about this.

5. The Congress declaration ought to be highly critical and skeptical about private sector actors being invited to the table where public health nutrition decisions are made. [This is why so many of us are skeptical about the SUN Initiative with its well exposed conflicts of interest. ((A. Gupta, The Scaling Up Nutrition (SUN) Movement Undermining Democracy and Sovereignty: A Case Study from India. Presented at the 'Multistakeholderism Critical Look' workshop, 18- 19 March 2019, TNI, Amsterdam))] What action points need to be pursued is yet another key discussion topic during the Congress.

6. As said, PICSOs have the crucial role in monitoring progress made in the progressive realization of this 10-year plan to fulfill the right to nutrition. Annual benchmarks of processes-set-in-motion have to be set so that these CSOs can assess progress, stagnation or retrogression on an annual basis with something like unequivocal shadow reports. The practicalities of such a roadmap need to be discussed in Brisbane.

7. The Committee on Food Security (CFS), including the Civil Society Mechanism (CSM) of the CFS, the UNSCN and others' contribution to the Decade is very important, BUT must be along the lines of what is said above. If they fall shy of achieving this, we will be discussing the same shortcomings by the end of the Decade. We cannot be doomed by and stuck in one more decade ultimately inconsequential in achieving its stated goals. At mid-term there still is a chance and our Congress can provide valuable inspiration and inputs for the needed changes in the next five years. 
8. Bottom line, from now on, actions called for must ultimately empower claim holders to demand their rights more vocally. This calls for a radical reinvigoration of the right to nutrition movement. Several sessions in our Congress will be addressing this. It is hoped that recommendations coming from there will find their way into the Congress declaration.

\section{Anybody for a Counterpoint? [Editor: responses can be submitted here:} https://worldnutritionjournal.org/index.php/wn/about/submissions]

Claudio Schuftan, Ho Chi Minh City

cschuftan@phmovement.

\section{A counterpoint from the Editor:}

My main concern is that you correctly say the HR approach will only work if a huge and successful effort can be made to raise awareness of claim holders and they are somehow inspired to demand their rights. But there seems to be a disconnect in this. Is there any way our Congress can help identify where the funds and the will to achieve this might be located to further the process of mobilizing them? Ultimately, funds will often have to be found from or with the concurrence of duty bearers! Otherwise, as the Commentary says, nothing will happen. Are they likely to approve funds and have the will to achieve the changes this commentary calls for? Or will they do so only in the early stages when it all seems harmless and likely to lead nowhere? 